\title{
Correction: Determination of metal ion content of beverages and estimation of target hazard quotients: a comparative study
}

\author{
Theresa Hague ${ }^{1}$, Andrea Petroczi ${ }^{1}$, Paul LR Andrews², James Barker ${ }^{3}$, Declan P Naughton ${ }^{1 *}$
}

\begin{abstract}
This is a correction to the following paper: Hague T, Petroczi A, Andrews PR, Barker J, Naughton DP: Determination of metal ion content of beverages and estimation of target hazard quotients: a comparative study. Chem Central J 2008, 2:13.
\end{abstract}

\section{Correction}

During preparation of a subsequent paper, we observed a computational error in the Target Hazard Quotients (THQ) listed in this work which have been inadvertently overestimated [1]. The overall results and conclusion of our paper with the corrected figures have remained valid. Corrections for Figures three, four and five; and Additional file three are given below in tabular form. The correct values with $\mathrm{EFr}=365$ days, $\mathrm{ED}_{\text {tot-male }}=$ 63.9 years and $\mathrm{ED}_{\text {tot-female }}=66.7$ years; $\mathrm{BW}_{\text {male }}=83.11$ $\mathrm{kg}, \mathrm{BW}_{\text {female }}=69.81 \mathrm{~kg}, \mathrm{AT}=6$ years and 30 years (non-carcinogenic) are shown in Tables 3 and 4 . In keeping with the conclusion published, THQ values of apple juice and stout have remained below 1 (Tables 1 and 2), whereas the combined THQ values for red wine (both intact and ultrafiltered) have exceeded the cutoff value of 1 , mainly owing to high $\mathrm{V}$ values (Tables 3 and 4). Although in keeping with the literature, THQ values were calculated for AT $=30$ years, given the effect metals are assumed to have on health and delayed onset, AT is likely to be below 30 years.

As noted in the paper, the THQ values calculated are concerning in that they are mainly above the safe level of THQ $\leq 1$, which premise holds for the wine with the adjusted THQ values. It must be emphasized that the THQ value is to be judged as either below or above 1 , where any value above 1 is a cause for health concern. It is notable that $\mathrm{i}$ ) choices in value input into averaging time (AT), ii) uncertainty factor regarding the oral reference dose (RfD) and iii) bioavailability can have signifi-

Table 1 Corrected THQ values for apple juice and stout (AT $=6$ years)

\begin{tabular}{lrrrr}
\hline Metal & THQ apple juice (male) & THQ apple juice (female) & THQ stout (male) & THQ Stout (female) \\
\hline $\mathrm{V}$ & 0.0092 & 0.0114 & 0.0365 & 0.0434 \\
\hline $\mathrm{Cr}^{*}$ & 0.0046 & 0.0057 & 0.0039 & 0.0046 \\
\hline $\mathrm{Mn}{ }^{*}$ & 0.0690 & 0.0858 & 0.0278 & 0.0331 \\
\hline $\mathrm{Ni}$ & 0.0103 & 0.0128 & 0.0006 & 0.0007 \\
\hline $\mathrm{Cu}$ & 0.0313 & 0.0389 & 0.0089 & 0.0106 \\
\hline $\mathrm{Zn}$ & 0.0111 & 0.0138 & 0.0025 & 0.0030 \\
\hline $\mathrm{Pb}$ & 0.0000 & 0.0000 & 0.0000 & 0.0000 \\
\hline \multicolumn{1}{c}{$\Sigma$} & 0.1355 & 0.1684 & 0.0802 & 0.0955 \\
\hline
\end{tabular}

* above working range

\footnotetext{
* Correspondence: D.Naughton@kingston.ac.uk

${ }^{1}$ School of Life Sciences, Kingston University, Kingston upon Thames, Surrey KT1 2EE, UK
} 
Table 2 Corrected THQ values for apple juice and stout (AT = 30 years)

\begin{tabular}{|c|c|c|c|c|}
\hline Metal & THQ apple juice (male) & THQ apple juice (female) & THQ stout (male) & THQ Stout (female) \\
\hline V & 0.0018 & 0.0023 & 0.0073 & 0.0087 \\
\hline $\mathrm{Cr}^{*}$ & 0.0009 & 0.0011 & 0.0008 & 0.0009 \\
\hline $\mathrm{Mn} *$ & 0.0138 & 0.0172 & 0.0056 & 0.0066 \\
\hline$\overline{\mathrm{Ni}}$ & 0.0021 & 0.0026 & 0.0001 & 0.0001 \\
\hline$\overline{\mathrm{Cu}}$ & 0.0063 & 0.0078 & 0.0018 & 0.0021 \\
\hline $\mathrm{Zn}$ & 0.0022 & 0.0028 & 0.0005 & 0.0006 \\
\hline $\mathrm{Pb}$ & 0.0000 & 0.0000 & 0.0000 & 0.0000 \\
\hline$\Sigma$ & 0.0271 & 0.0337 & 0.0160 & 0.0191 \\
\hline
\end{tabular}

* above working range

Table 3 Corrected THQ values for intact and ultrafiltered red wine (AT = 6 years)

\begin{tabular}{lrrrr}
\hline Metal & THQ intact (male) & THQ Intact (female) & THQ ultrafiltered (male) & THQ ultrafiltered (female) \\
\hline $\mathrm{V}$ & 4.5114 & 5.6063 & 4.0552 & 5.0393 \\
\hline $\mathrm{Cr}{ }^{*}$ & 0.0213 & 0.0265 & 0.0241 & 0.0300 \\
\hline $\mathrm{Mn}{ }^{*}$ & 0.5620 & 0.6984 & 0.5454 & 0.6778 \\
\hline $\mathrm{Ni}$ & 0.0496 & 0.0617 & 0.0422 & 0.0525 \\
\hline $\mathrm{Cu}$ & 0.2429 & 0.3018 & 0.0189 & 0.0234 \\
\hline $\mathrm{Zn}$ & 0.1250 & 0.1553 & 0.1258 & 0.1564 \\
\hline $\mathrm{Pb}$ & 0.0001 & 0.0002 & 0.0000 & 0.0000 \\
\hline \multicolumn{1}{c}{} & 5.5125 & 6.8502 & 4.8117 & 5.9794 \\
\hline
\end{tabular}

* above working range

Table 4 Corrected THQ values for intact and ultrafiltered red wine (AT = 30 years)

\begin{tabular}{|c|c|c|c|c|}
\hline Metal & THQ intact (male) & THQ Intact (female) & THQ ultrafiltered (male) & THQ ultrafiltered (female) \\
\hline V & 0.9023 & 1.1213 & 0.8110 & 1.0079 \\
\hline $\mathrm{Cr}^{*}$ & 0.0043 & 0.0053 & 0.0048 & 0.0060 \\
\hline$M n^{*}$ & 0.1124 & 0.1397 & 0.1091 & 0.1356 \\
\hline$\overline{\mathrm{Ni}}$ & 0.0099 & 0.0123 & 0.0084 & 0.0105 \\
\hline$\overline{\mathrm{Cu}}$ & 0.0486 & 0.0604 & 0.0038 & 0.0047 \\
\hline$\overline{Z n}$ & 0.0250 & 0.0311 & 0.0252 & 0.0313 \\
\hline$\overline{\mathrm{Pb}}$ & 0.0000 & 0.0000 & 0.0000 & 0.0000 \\
\hline$\Sigma$ & 1.1025 & 1.3700 & 0.9623 & 1.1959 \\
\hline
\end{tabular}

* above working range

cant effect on the THQ value. The THQ is designed to be a conservative estimate. However, further research is required in order to provide guidance on appropriate value choices.

\section{Author details}

${ }^{1}$ School of Life Sciences, Kingston University, Kingston upon Thames, Surrey KT1 2EE, UK. 'Division of Basic Medical Sciences, St George's University of London, London SW17 ORE, UK. ${ }^{3}$ School of Pharmacy and Chemistry, Kingston University, London KT1 2EE, UK.

\section{Competing interests}

The authors declare that they have no competing interests.
Reference

1. Hague T, Petroczi A, Andrews PR, Barker J, Naughton DP: Determination of metal ion content of beverages and estimation of target hazard quotients: a comparative study. Chem Central J 2008, 2:13.

doi:10.1186/1752-153X-4-2

Cite this article as: Hague et al:: Correction: Determination of metal ion

content of beverages and estimation of target hazard quotients: a

comparative study. Chemistry Central Journal 2010 4:2 